University of Wollongong

Research Online

Australian Institute for Innovative Materials -

Papers

Australian Institute for Innovative Materials

$1-1-2017$

\title{
Nanoscale analyses of the surface structure and composition of biochars extracted from field trials or after co-composting using advanced analytical electron microscopy
}

B Archanjo

Instituto Nacional de Metrologia

M Mendoza

Instituto Nacional de Metrologia

M Albu

Austrian Cooperative Research

David R. G Mitchell

University of Wollongong, dmitchel@uow.edu.au

N Hagemann

University of Tuebingen

See next page for additional authors

Follow this and additional works at: https://ro.uow.edu.au/aiimpapers

Part of the Engineering Commons, and the Physical Sciences and Mathematics Commons

Research Online is the open access institutional repository for the University of Wollongong. For further information contact the UOW Library: research-pubs@uow.edu.au 


\title{
Nanoscale analyses of the surface structure and composition of biochars extracted from field trials or after co-composting using advanced analytical electron microscopy
}

\author{
Abstract \\ Biochars have been recognized as an important material to improve soil properties. In a number of \\ studies their beneficial properties have been found to increase with residence time in soil and during the \\ composting process. The beneficial properties have been correlated with surface functional groups \\ resulting from the interactions between char particles, inorganic and organic matter in the soil and soil \\ biota. These interactions result in the formation of organo-mineral phases on the internal and external \\ surfaces of the biochar. A paucity of information exists, particularly from longer-term field trials, on \\ organo-mineral phases present on both the internal and external surfaces of the biochar. To characterize \\ the structure of, and interface between, the carbon and mineral phases, we examined biochars recovered \\ from two field trials and after composting from different countries using high resolution scanning \\ electron microscopy (SEM), atomic resolution transmission electron microscopy (TEM) and scanning \\ TEM (STEM), energy electron loss spectroscopy (EELS) and energy dispersive X-ray spectroscopy (EDS) \\ at resolutions of 1-20 nm. The work revealed the formation of porous agglomerates of different minerals/ \\ inorganic compounds bound together with organic compounds on the surfaces of the biochar. In some \\ cases, these agglomerates were bound together to form organo-mineral associations. The analyses also \\ showed that the organic compounds containing both $\mathrm{N}$ and $\mathrm{C}$ functional groups and mixed valence iron \\ oxide nanoparticles are possibly interacting with the organic compounds. The analysis also showed the \\ formation of pores at the interface of the carbon matrix and organo-mineral aggregates. \\ Disciplines \\ Engineering | Physical Sciences and Mathematics

\section{Publication Details} \\ Archanjo, B. S., Mendoza, M. E., Albu, M., Mitchell, D. R. G., Hagemann, N., Mayrhofer, C., Mai, T., Weng, Z., \\ Kappler, A., Behrens, S., Munroe, P., Achete, C. A., Donne, S., Araujo, J. R., van Zwieten, L., Horvat, J., \\ Enders, A. \& Joseph, S. (2017). Nanoscale analyses of the surface structure and composition of biochars \\ extracted from field trials or after co-composting using advanced analytical electron microscopy. \\ Geoderma, 294 70-79.

\section{Authors} \\ B Archanjo, M Mendoza, M Albu, David R. G Mitchell, N Hagemann, C Mayrhofer, Thi Mai, Zhe Weng, A \\ Kappler, S Behrens, Paul R. Munroe, C Achete, Scott Donne, J R. Araujo, Lukas van Zwieten, Josip Horvat, \\ A Enders, and Stephen D. Joseph
}




\section{Nanoscale Analyses of the Surface Structure and Composition of Biochars Extracted from Field Trials or after Co-composting Using Advanced Analytical Electron Microscopy}

B. S. Archanjo ${ }^{1}$, M. E. Mendoza ${ }^{1}$, M. Albu ${ }^{2}$, D. R. G. Mitchell ${ }^{3}$, N. Hagemann ${ }^{4}$, C Mayrhofer ${ }^{2}$, Thi Lan Anh Mai ${ }^{5}$, ZheWeng $^{6}$, A. Kappler ${ }^{4}$, S. Behrens ${ }^{7}$, P. Munroe ${ }^{8}$, C. A.

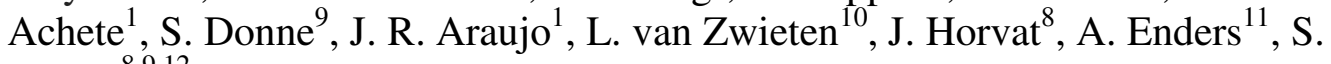
Joseph $^{8,9,12}$

1 Divisão de Metrologia de Materiais, Instituto Nacional de Metrologia, Qualidade e Tecnologia, Duque de Caxias, RJ 25250-020, Brazil

${ }^{2}$ Austrian Cooperative Research, Centre for Electron Microscopy and Nanoanalysis, Graz, Austria

${ }^{3}$ Electron Microscopy Centre, AIIM, University of Wollongong, Wollongong NSW, 2519, Australia

${ }^{4}$ Geomicrobiology, Center for Applied Geoscience, University of Tuebingen, Germany

${ }^{5}$ Faculty of Environment and Earth Sciences - Thai Nguyen University of Sciences, Thai Nguyen, Vietnam

${ }^{6}$ Graham Centre for Agricultural Innovation, Charles Sturt University, North Wagga, NSW 2678, Australia

7 Department of Civil, Environmental, and Geo-Engineering, University of Minnesota, Minneapolis, MN 55455, United States

${ }^{8}$ Department of Physics and Institute for Superconducting and Electronic Materials, University of Wollongong, Wollongong NSW, 2522, Australia

${ }^{9}$ Discipline of Chemistry University of Newcastle, Callaghan, NSW 2308, England

10 NSW Department of Primary Industries, Wollongbar Primary Industries Institute, Wollongbar, NSW 2477, Australia

${ }^{11}$ Department of Crop and Soil Sciences, Cornell University, Ithaca, NY 14853, United States

${ }^{12}$ School of Materials Science and Engineering, University of New South Wales, NSW 2052, Australia

\section{Summary}

Biochars have been recognized as an important material to improve soil properties. In a number of studies their beneficial properties have been found to increase with residence time in soil and during the composting process. The beneficial properties have been correlated with surface functional groups resulting from the interactions between char particles, inorganic and organic matter in the soil and soil biota. These interactions result in the formation of organo-mineral phases on the internal and external surfaces of the biochar. A paucity of information exists, particularly from longer-term field trials, on organo-mineral phases present on both the internal and external surfaces of the biochar. To characterize the structure of, and interface between, the carbon and mineral phases, we examined biochars recovered from two field trials and after composting from different countries using high resolution scanning electron microscopy (SEM), atomic resolution transmission electron microscopy (TEM) and scanning TEM (STEM), 
energy electron loss spectroscopy (EELS) and energy dispersive X-ray spectroscopy (EDS) at resolutions of 1-20 $\mathrm{nm}$. The work revealed the formation of porous agglomerates of different minerals/inorganic compounds bound together with organic compounds on the surfaces of the biochar. In some cases, these agglomerates were bound together to form organo-mineral associations. The analyses also showed that the organic compounds contained both $\mathrm{N}$ and $\mathrm{C}$ functional groups and mixed valence iron oxide nanoparticles are possibly interacting with the organic compounds. The analysis also showed the formation of pores at the interface of the carbon matrix and organomineral aggregates.

\section{Keywords}

Biochar, electron microscopy, organo-mineral associations, micro-aggregates, carbon and nitrogen functional groups

Corresponding authors:

Braulio S. Archanjo - bsarchanjo@inmetro.gov.br

Stephen Joseph - joey.stephen@gmail.com

\section{Introduction}

Biochar is defined as charred organic matter applied in agriculture. It is recognized as an important material to improve a range of soil properties, by increasing the efficiency of $\mathrm{N}$ and $\mathrm{P}$ chemical fertilisers and by enhancing the properties of compost (Lehmann and Joseph, 2009). However, as soon as biochar is amended to soil or composting feedstock, it is subjected to a range of physical, chemical and biological interactions. Biochar can be fragmented into smaller particles as soon as it interacts with water (physical disintegration), which is suggested to hardly alter the carbon speciation of the biochar (Spokas et al., 2014). Biochar will sorb a broad range of organic and inorganic compounds from soil or compost (Borchard et al., 2014; Hale et al., 2013; Hale et al., 2015) and might be involved in acid-base - reduction of biochar $\mathrm{pH}$ during aging in soil, cf. (Heitkötter and Marschner, 2015; Spokas, 2013) - as well as redox reactions (Klüpfel et al., 2014; Quin et al., 2015). Biochar interacts with soil fauna, microorganisms and roots (Lehmann et al., 2011), especially, it can be a habitat for microorganisms (Quilliam et al., 2013). The sum of these processes results in an alteration of the biochar. To some extent, this alteration can be characterized as an 
oxidation of the biochar surface (Cheng et al., 2006; Wiedner et al., 2015). A range of studies has shown that the structure and properties of biochars evolve in a complex, spatially heterogeneous manner beyond the oxidation of carbon. This involves the interaction (sorption) with non-biochar organic and inorganic matter (Araujo et al., 2014; Joseph et al., 2010; Singh and Cowie, 2014) and complex biotic and abiotic redox reactions (Joseph et al., 2015; Kappler et al., 2014; Pagano et al., 2016). Thus, (electron) microscopy and related techniques are important tools to identify the spatial distribution of these processes on the biochar surface, and also can be used to identify the nature of these alterations.

Detailed evaluation of biochar after incorporating into the soil for more than one year has been carried out using a range of techniques including transmission electron microscopy (TEM) and scanning electron microscopy (SEM). Chia et al. (2012) characterized the interfaces between carbon-rich and mineral-rich regions of particles collected from the Terra Preta soils from the Amazon. A key finding was the appearance of $\mathrm{Fe}$ and $\mathrm{Mn}$ nanoparticles around the surface of the carbon-rich regions and the high concentration of $\mathrm{Ca}$ in the amorphous carbon that surrounded mineral phases. These nanoparticles were shown to be redox-active (Joseph et al., 2015).

Archanjo et al. (2014 and 2015) and Jorio et al. (2012) examined the carbon-rich core as well as the organo-mineral shell around these Terra Preta particles. They were able to map the distribution of carbon functional groups around sub-micron carbon particles using monochromated electron energy-loss spectroscopy (EELS). These studies showed that the carbon matrix is not homogenous throughout a single particle. Also, using energy dispersive X-ray spectroscopy (EDS), the carbon particles showed high concentrations of Ca. In addition, X-ray photoelectron spectroscopy (XPS) and Raman spectroscopy both showed biochar particles to have higher carbon aromaticity in their core than at the surface.

Lin et al. (2012) examined the surface of biochar produced from chicken litter that was collected after being in the soil for one year. This work was complemented by examination of the biochar surface with XPS. They found that organo-mineral layers had been formed on the surface of the biochar and that these were characterized by formation of a range of sub-100 $\mathrm{nm}$ mineral particles surrounded by amorphous carbon to form micro-aggregates. Pores ranging in size from 1 to $100 \mathrm{~nm}$ were observed between the biochar and the organo-mineral layer and there was an increase in carboxyl $(\mathrm{COOH})$ and amino $\left(\mathrm{NH}_{2}\right)$ functional groups. More detailed TEM analysis of the 
interfaces between poultry litter and paper sludge biochar and organo-mineral complexes, which had been in the soil for two years, was also undertaken. It has been hypothesised that the long-lasting properties of the biochars were due to the formation of this nutrient-rich functionalised layers (Joseph et al., 2013).

Although a number of studies on the characteristics of field applied biochars can be found in the literature, a detailed analysis of the interfaces between the biochar and organo-mineral phases, as well as the strengths and weaknesses of each microscopy and sample preparation methods, have not been yet undertaken. Studies using high resolution SEM or atomic resolution TEM/STEM methods with spectroscopic techniques such as EELS and EDS at resolutions of 1-20 nm can be very useful for soil science research. In fact, such studies would provide insights into the process of stabilisation of the biochar and its long-term agronomic benefits. It will also allow an evaluation of the various sample preparation methods and imaging and analysis techniques, to understand which are best suited to characterising these complex materials.

This paper presents the results of the observations and measurements of three very different biochars produced in different continents. Two of these biochars were extracted from field trials in two different soil types and the third was extracted from a high quality mixed manure/biochar compost. The questions to be addressed by this study include:

1. Can the nanometer-scale chemical and structural information acquired by SEM and TEM provide insights into the complex reactions which take place on the external and internal surfaces of biochar in soil and compost?

2. Are there similarities between the organomineral layers formed on different biochars extracted from different soils and from compost at the nanometer scale?

3. What are the optimal microscopic techniques to obtain images and spectra at high resolution without contamination and damage of the specimen?

\section{Materials and Methods}

Three very distinct biochars were examined. Two were derived from various soils and the third from a composting experiment. These biochars have been shown to increase 
plant growth (Mohammadi et al., 2016) and total soil carbon content (Slavich et al., 2013) under field conditions. Biochars extracted manually from the ground/compost pile were thoroughly washed with demineralized water on a 100 micron sieve and then dried at $50^{\circ} \mathrm{C}$ in an oven for 24 hours.

Mineral-rich biochar (RCBS) was produced in North Vietnam. A mixture of rice straw and husk coated in clay, along with wood and bamboo was pyrolysed in a top lit updraft gasifier drum oven (TLUD) at approximately $450^{\circ} \mathrm{C}$ (Mohammadi et al., 2016) to produce a mineral-rich biochar (RCBS) which was then added to manure and composted for 45 days. This mixture was applied to rice paddies and was extracted after 2.5 years. The basic properties of the pristine biochar were $\mathrm{pH} 9.8$, total $\mathrm{C} 54 \%$; nitrogen $0.82 \%$, ash content $23 \%$, phosphorous $5.12 \mathrm{~g} / \mathrm{kg}$ and potassium $25 \mathrm{~g} / \mathrm{kg}$. The soil was loamy sand, the $\mathrm{pH}_{\mathrm{KCl}}(1: 2.5) 5.3$ and organic carbon (OC) $1.23 \%$.

Green waste biochar (GWS) was from a field trial in Wollongbar NSW Australia (Slavich et al., 2013), after being incorporated for 9.5 years. This biochar was produced at $550{ }^{\circ} \mathrm{C}$, it has a relatively low ash and high carbon content $(76 \%)$. Details of this biochar are provided elsewhere (Slavich et al., 2013; Weng et al., 2015). The basic properties of the pristine biochar were: $\mathrm{pH} 7.8$, total $\mathrm{C} 76 \%$, nitrogen $0.61 \%$, ash content $7.6 \%$, phosphorous $0.19 \mathrm{~g} / \mathrm{kg}$ and potassium $1.7 \mathrm{~g} / \mathrm{kg}$. The field experiment was conducted on a mixed $\mathrm{C}_{3} / \mathrm{C}_{4}$ vegetated rhodic Ferralsol. The soil was acidic $(\mathrm{pH} 4.5 ; 1: 5$ $\mathrm{CaCl}_{2}$ ) with $4.5 \%$ total carbon content.

A wood biochar (WC) was produced from branches taken after the tree was pruned in a Kon-Tiki kiln (Cornelissen et al., 2016) at approximately $700{ }^{\circ} \mathrm{C}$. It was co-composted under aerobic conditions with manure at sub-industrial scale for 63 days during a composting field experiment at the Ithaka Institute in Arbaz and St. Léonard, Switzerland. The compost windrow $\left(20 \mathrm{~m}^{3}\right)$ reached a maximum temperature of $65{ }^{\circ} \mathrm{C}$. The basic properties of the pristine biochar were: $\mathrm{pH} 8.5$, total $\mathrm{C} 77 \%$, nitrogen $0.75 \%$, ash content $18.4 \%$, phosphorous $2.1 \mathrm{~g} / \mathrm{kg}$ and potassium $4.8 \mathrm{~g} / \mathrm{kg}$.

Further basic characteristics and information on the processing and characterization techniques of these biochars are given in Table 1, which summarizes the spectromicroscopic techniques and respective sample preparation methods applied to the biochars. The microscopy was carried out in 4 different universities. Each of these 
centres has different microscopes and different techniques to measure the properties of the surface and the internal structures and composition of field applied biochars. This research is part of an ongoing effort to refine microscopy techniques for examining nanoscale processes on the surface of biochars. Detailed microscopy and spectroscopic methods are provided in the Supporting Information. 
Table 1. Biochar processing and characterization techniques

\begin{tabular}{|c|c|c|c|c|c|}
\hline Biochar & Aging & $\begin{array}{l}\text { Microscopy } \\
\text { Sample } \\
\text { Preparation }\end{array}$ & Microscope & Aim & Results \\
\hline \multirow{2}{*}{$\begin{array}{c}\text { RCBS } \\
\text { Vietnam } \\
\text { Biochar } \\
\text { sample } \\
\text { Clay/Fe } \\
\text { Oxide } \\
\text { enhanced } \\
\text { mixed rice } \\
\text { straw bamboo } \\
\text { wood biochar }\end{array}$} & \multirow{2}{*}{$\begin{array}{l}\text { Rice paddy } \\
2.5 \text { years, } \\
\text { field trial } \\
\text { (Mohammadi } \\
\text { et al., 2016) }\end{array}$} & $\begin{array}{l}\text { Coating with } \\
\text { chromium }\end{array}$ & $\begin{array}{l}\text { Zeiss Sigma } \\
\text { SEM with } \\
\text { Bruker EDS }\end{array}$ & $\begin{array}{l}\text { Imaging } \\
\text { and } \\
\text { elemental } \\
\text { mapping of } \\
\text { surface at } \\
\text { sub-micron } \\
\text { scale }\end{array}$ & Fig. 1 \\
\hline & & $\begin{array}{c}\text { Micro- } \\
\text { fragmentation } \\
\text { in ethanol with } \\
\text { mortar and } \\
\text { pestle or } \\
\text { embedding in } \\
\text { Spurr resin and } \\
\text { ultramicrotomy }\end{array}$ & $\begin{array}{c}\text { JEOL } \\
\text { ARM200F } \\
\text { TEM, } \\
\text { STEM, } \\
\text { EELS and } \\
\text { EDS }\end{array}$ & $\begin{array}{l}\text { Elemental } \\
\text { analyses, C } \\
\text { and Fe } \\
\text { chemical } \\
\text { bond } \\
\text { information }\end{array}$ & Fig. 2 \\
\hline \multirow[b]{2}{*}{$\begin{array}{c}\text { GWS } \\
\text { Wollongbar } \\
\text { Green waste } \\
\text { Biochar }\end{array}$} & \multirow[b]{2}{*}{$\begin{array}{l}\text { Pasture soil, } \\
\text { field trial, } 9.5 \\
\text { years } \\
\text { (Slavich et } \\
\text { al., 2013) }\end{array}$} & $\begin{array}{l}\text { Coating with } \\
\text { chromium }\end{array}$ & $\begin{array}{l}\text { Zeiss Sigma } \\
\text { SEM with } \\
\text { Bruker EDS }\end{array}$ & $\begin{array}{c}\text { Imaging } \\
\text { and } \\
\text { elemental } \\
\text { analyses of } \\
\text { surface }\end{array}$ & Fig. 3 \\
\hline & & $\begin{array}{c}\text { Micro- } \\
\text { fragmentation } \\
\text { in ethanol with } \\
\text { mortar and } \\
\text { pestle or FIB } \\
\text { cross- } \\
\text { sectioning }\end{array}$ & $\begin{array}{l}\text { FEI Titan 80- } \\
\text { 300, TEM, } \\
\text { STEM, } \\
\text { EELS and } \\
\text { EDS }\end{array}$ & $\begin{array}{l}\text { Mapping of } \\
\text { elements, } \mathrm{C} \\
\text { and Fe } \\
\text { chemical } \\
\text { bond } \\
\text { information } \\
\text { down to } \\
\text { nanoscale }\end{array}$ & $\begin{array}{c}\text { Figs. } 4 \\
\text { and } 5\end{array}$ \\
\hline \multirow{2}{*}{$\begin{array}{c}\text { WC } \\
\text { Kon-Tiki } \\
\text { Composted } \\
\text { Wood } \\
\text { Biochar } \\
\text { sample }\end{array}$} & \multirow{2}{*}{$\begin{array}{c}\text { Co- } \\
\text { composted in } \\
\text { aerobic } \\
\text { manure } \\
\text { composted }\end{array}$} & $\begin{array}{l}\text { Conductive } \\
\text { Carbon paint. }\end{array}$ & $\begin{array}{c}\text { Zeiss Sigma } \\
\text { SEM with } \\
\text { Bruker EDS }\end{array}$ & $\begin{array}{c}\text { Imaging } \\
\text { and } \\
\text { elemental } \\
\text { analyses of } \\
\text { surface } \\
\end{array}$ & Fig. 6 \\
\hline & & $\begin{array}{l}\text { Gold coating of } \\
\text { whole particles, } \\
\text { embedding in } \\
\text { epoxy resin and } \\
\text { ultramicrotomy }\end{array}$ & $\begin{array}{c}\text { FEI Titan G2 } \\
\text { 60-300, } \\
\text { TEM, } \\
\text { STEM, } \\
\text { EELS and } \\
\text { EDS }\end{array}$ & $\begin{array}{l}\text { Mapping of } \\
\text { elements at } \\
\text { nanoscale, } \\
\mathrm{C} \text { and } \mathrm{N} \\
\text { chemical } \\
\text { bond } \\
\text { information }\end{array}$ & $\begin{array}{c}\text { Figs. } 7 \\
\text { and } 8\end{array}$ \\
\hline
\end{tabular}




\section{Results}

\subsection{Analysis of Mineral Rich Biochar (RCBS)}

Figure 1a is a SEM secondary electron (SE) image which clearly shows that sub-micron particles have formed inside the pores of the woody biochar. There is a cylindrical structure (ca. $4 \mu \mathrm{m}$ long) enveloped with sub-micron particles which could be either a microbe or a coarse mineral particle. Some of these sub-micron particles have bonded to the walls of the biochar. Besides carbon and oxygen, the main elements in the biochar (EDS spectrum inset) are $\mathrm{Fe}, \mathrm{Si}, \mathrm{Al}, \mathrm{K}$ with lower amounts of $\mathrm{Ca}$ and $\mathrm{Ti}$. $\mathrm{Cr}$ from the applied conductive coating was also detected.

Figure $1 b$ is a high magnification SE image of the outer surface of the pore; it shows the formation of layers on the biochar pore wall surface (arrowed). These layers contain different mineral phases rich in $\mathrm{Al}, \mathrm{Si}, \mathrm{Fe}$ (EDS analysis not shown). It suggests that the main sub-micron inorganic phases contain oxides of Fe/Al with small amounts of Si. The 100-200 nm Fe/Al layer (white layer indicated by a black arrow in Fig. 1b) on the top of the biochar wall charges under the electron beam. Its low conductivity could indicate that bonding between the carbon matrix and the organo-mineral phases is very weak (electrons are not readily conducted to the biochar). Fig. 1c shows a SE image of the surface of a pore that has been filled with a mixture of organic and mineral matter and on top of this are various inorganic phases which are rich in $\mathrm{Fe}, \mathrm{Si}$ and $\mathrm{Al}$ as observed in the overlaid EDS elemental map. These inorganic phases have bonded together to form a micro-aggregate. 

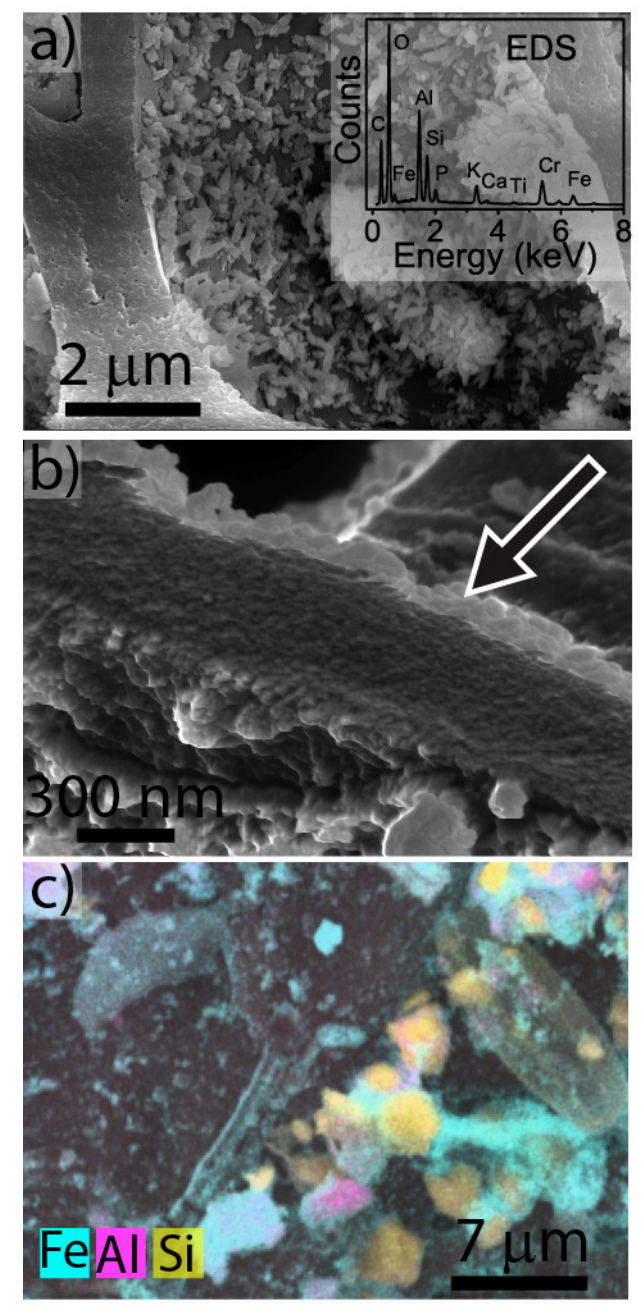

Figure 1. SEM secondary electrons imaging of the carbon matrix-organo-mineral interface of RCBS. a) Inorganic precipitates inside a large elliptical pore of woody biochar; inset shows EDS spectrum collected from the whole area inside the pore. b) Detail of the organo-mineral layer (bright layer indicated by the arrow) formed on the pore walls; c) Image of a pore covered with micron and sub-micron sized mineral and organo-mineral particles and EDS elemental map, showing Fe, Al and Si distributions.

Figure $2 \mathrm{a}$ is a TEM bright field image of a section of a RCBS particle that has been embedded in Spurr's resin and microtomed. The biochar itself was sectioned with minor damage caused by chattering of the blade and specimen compression during sectioning result in some distortion. The real advantage of this technique is the providing relatively large area sections which show both the macroscopic and microscopic aspects of the porous structure. Detailed characterization of the mineral/inorganic compounds that exists on the surfaces of the pores is readily achieved. Region I ( $10 \mu \mathrm{m}$ in diameter) in Fig. $2 \mathrm{a}$ is rich in both minerals/inorganic compounds which are attached to the carbon 
matrix (region II). A porous region exists between region II and a highly porous region III. This porous region consists of both a carbon matrix and a range of minerals/inorganic compounds.'

In Fig. 2b, a BF-TEM image shows details of large macropores present in the biochar (between regions II and III in Fig. 2a). The EEL spectrum of the biochar carbon in Fig. $2 \mathrm{~b}$ inset shows a core loss $\mathrm{C}$ K-ionization edge (or C K-edge) similar to carbon structures in the intermediate graphitization state (Ribeiro-Soares et al., 2015; Vallerot et al., 2006) where $1 \mathrm{~s} \rightarrow \pi^{*}$ transition $(285 \mathrm{eV}$ ) is well defined as a sharp peak on the leading edge of the carbon peak while the $1 \mathrm{~s} \rightarrow \sigma^{*}$ (c.a. $292 \mathrm{eV}$ ) is broad, when compared with graphite, which has a sharper $1 \mathrm{~s} \rightarrow \sigma^{*}$ peak. Joseph et al (2010) measured a relatively high concentration of $\mathrm{C}-\mathrm{O}$ and $\mathrm{C}=\mathrm{O}$ on the surface of fresh greenwaste biochar utilising XPS and $\mathrm{COOH}, \mathrm{C}-\mathrm{O}$ and $\mathrm{C}=\mathrm{O}$ for greenwaste biochar extracted from the soil after 1 and 2 years in the soil at peaks between 286.5-289.2 eV (Joseph et al., 2010). Organic functional groups are difficult to detect in EELS, since many of the species are damaged or volatized by the high energy electron beam. Cooling the specimen to liquid nitrogen temperature using an in-situ cooling holder is effective at both reducing the mobility of hydrocarbon species and at reducing beam damage (Mitchell, 2015). Due to the complex chemistry and especially after soil/compost exposure, such compounds are invariably present in the biochar.

A STEM-BF image (Fig. 2c) shows an organo-mineral micro-agglomerate layer on the surface of a biochar pore from Fig. 2a. Within this layer a dark rod-like particle (Fig. 2c arrowed) is rich in iron ( $\mathrm{Fe} \mathrm{L}_{2,3}$ of arrowed region in Fig. 2c inset top right, and EDS inset bottom right). Comparison of the $\mathrm{Fe} \mathrm{L}_{2,3}$ edge shape with those from reference spectra acquired from $\mathrm{Fe}_{2} \mathrm{O}_{3}$ and $\mathrm{Fe}_{3} \mathrm{O}_{4}$ (not shown), suggests this phase is $\mathrm{Fe}_{3} \mathrm{O}_{4}$, due to the absence of distinct peak half way up the leading edge of the main $\mathrm{Fe}_{2} \mathrm{~L}_{2}$ peak. EDS shows that there are also small quantities of $\mathrm{Al} / \mathrm{Si} / \mathrm{O}$ and possibly $\mathrm{Fe} / \mathrm{P}$ or $\mathrm{Ca} / \mathrm{P}-$ containing phases around the $\mathrm{Fe} / \mathrm{O}$ particle. These minerals are held together by amorphous carbon to form an organo-mineral micro-agglomerate. Fig. 2d corresponds to an atomic resolution STEM-HAADF (high-angle annular dark-field) image of the edge of the Fe/O particles observed in Fig. 2c (area inside the red square). Analysis of the interplanar spacings found in this region showed better agreement with those of $\mathrm{Fe}_{3} \mathrm{O}_{4}$ than with those for $\mathrm{Fe}_{2} \mathrm{O}_{3}$ - supporting the EELS-based identification. 

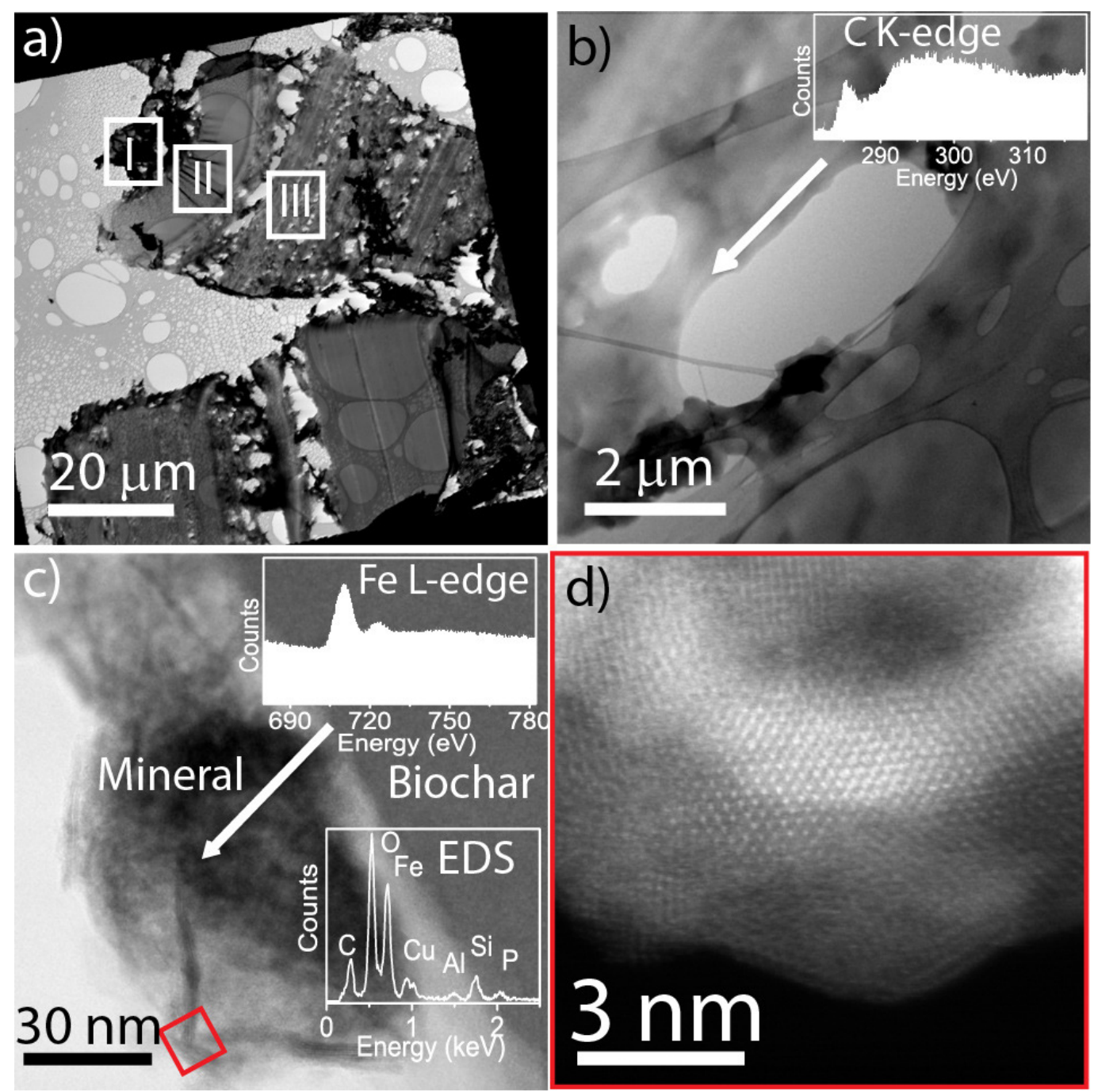

Figure 2. TEM analyses of the organo-mineral interface in RCBS. a) Low magnification BF-TEM image showing a general view of the microtomed sample. b) BF-TEM image showing details of large macropores present between the organo-mineral layer and the biochar (regions III and II in a). Inset is a C K-edge EEL spectrum from the carbon-rich matrix. c) BF-STEM image of the complex micro-agglomerate layer that has formed on the surface of the biochar. Insets: top $\mathrm{Fe} \mathrm{L}_{2,3}$-edge EEL spectrum from the region arrowed - edge shape is typical of $\mathrm{Fe}_{3} \mathrm{O}_{4}$; bottom EDS spectrum from the same region as EELS showing strong Fe and $\mathrm{O}$ signals; $\mathrm{Al}, \mathrm{Si}$, and $\mathrm{P}$ were also detected. d) Atomic resolution STEM-HAADF detail of the boxed region (red) in c) showing interplanar spacings consistent with $\mathrm{Fe}_{3} \mathrm{O}_{4}$.

\subsection{Analysis of Green Waste Biochar (GWS)}


Fig. 3 shows SE images and corresponding EDS analyses of the organo-mineral phase observed on the surface and in the pores of the GWS . Fig. 3a shows a cross-section through the original surface. An organo-mineral layer has coated the surface of the biochar (top half of Fig. 3a) and large internal pores from the original wood structure can be seen in the lower half of the image. EDS analysis (Fig. 3a inset) of the mineral layer shows a high concentration of $\mathrm{Al} / \mathrm{Si} / \mathrm{O}$ with smaller amounts of $\mathrm{Ca} / \mathrm{P} / \mathrm{Fe}$. The carbon matrix has retained the original phloem and xylem vascular structure (lower half of Fig. 3a). These are somewhat deformed and rounded by the subsequent processing. Figure $3 b$ reveals the internal structure of one of these pores. Sub-micron minerals and/or inorganic compounds coat the surface of the pore, and EDS (Fig. 3b inset) shows it to be rich in $\mathrm{K}, \mathrm{Ca}$ and $\mathrm{P}$.
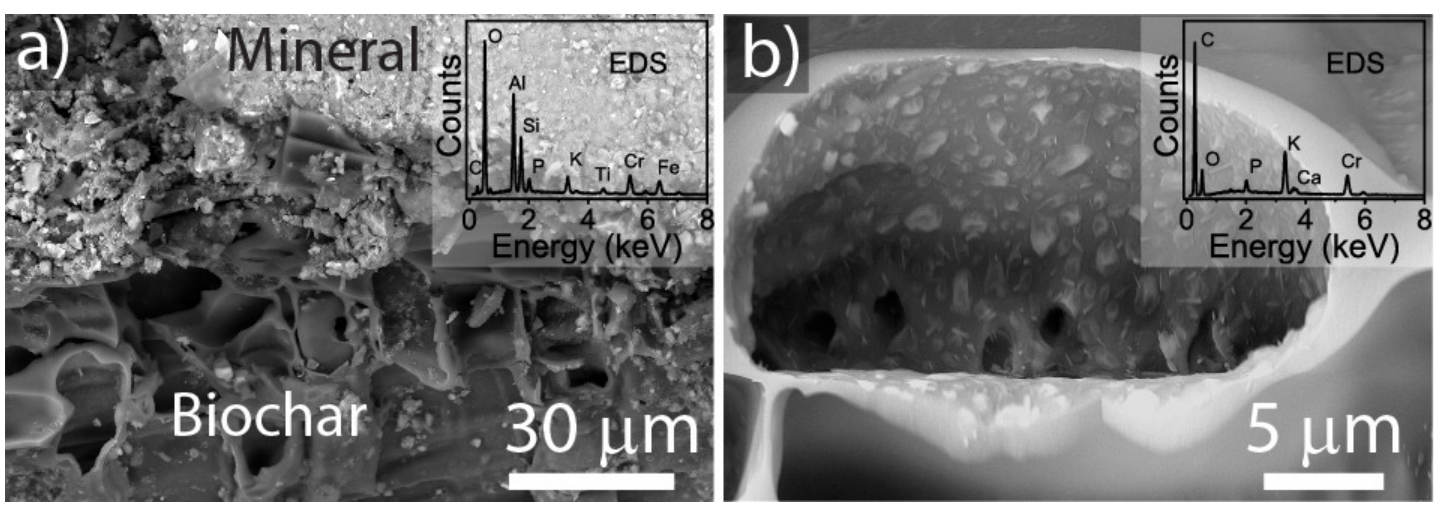

Figure 3. SEM SE images of the organo-mineral/carbon matrix interface in GWS. a) SE image of the organo-mineral layer on the particle surface (top) and the underlying biochar porous matrix (bottom). The inset shows the EDS analysis of the organomineral layer. b) An image of an internal pore coated in organic and mineral matter EDS spectrum of this area is shown inset.

Figure 4 shows results from the analysis of the surface of a biochar particle that has reacted with a range of organic and mineral components in the soil over a 9.5 year period. Fig. 4a is a STEM-HAADF image of a surface of the field applied biochar. The image shows the underlying porous carbon matrix and a partial covering by a layer of mineral/inorganic compounds. This mineral/inorganic coating is porous, but intimately attached to the biochar substrate (see Fig. S1 in the Supporting Information). An EDS spectrum image of the region inside the black rectangle in Fig. 4a is shown in Fig. 4b. The average EDS spectrum (Fig. 4b top) shows the mineral phase to be rich in $\mathrm{C}, \mathrm{O}, \mathrm{Al}$, $\mathrm{Si}$ and $\mathrm{P}$ with a small amount of Fe. The corresponding elemental maps, showing the 
distribution of these elements, are shown in Fig. 4b, bottom. These maps show that the large mineral clusters are mostly Al-Si oxides/hydroxides. Discrete Fe-rich regions are located within these clusters. Phosphorous is also present in the biochar matrix. Other areas examined revealed that many of these mineral/inorganic phases are bound together by an amorphous carbon glue-like layer (Fig. S2 shows another analysed region) to form micro-agglomerates.

A carbon K-edge EELS signal was collected at the same time as the EDS spectrum image. Fig 4c shows EEL spectra (top) and EELS maps (bottom), acquired from the black rectangle in Fig. 4a. The upper (blue) spectrum is the sum of the spectra collected from near the biochar-mineral interfaces, indicated by arrows in the EELS map I. The lower spectrum (black line) in Fig. $4 c$ is the sum of spectra acquired at the centre of the black rectangle in Fig. 4a. An increase in the signal intensity at around $285 \mathrm{eV}$ occurs in the near-interface spectrum (top blue) when compared to the lower spectrum. The carbon functional group producing a peak at this energy is aromatic carbon $(\mathrm{C}=\mathrm{C})$. The map I, labelled as aromatic, was generated taking the integrated signal from the $1 \mathrm{eV}$ window centred at c.a. $285 \mathrm{eV}$. This energy window, also labelled as I, is marked on the EEL spectra in Fig. 4c. All spectra were normalised using the C K-edge integrated intensity, the cross-hatched area labelled as II in the spectrum in Fig. 4c. In addition, the C K-edge integrated intensities are used to generate the carbon map II, which shows the carbon spatial distribution. There is a significant peak at $286.5 \mathrm{eV}$, which is usually present in fresh biochar (Archanjo et al., 2015) and is indicative of a range of C/O functional groups in the carbon matrix.

Fe L-edge EELS spectrum image data were acquired from the lower region of interest in Fig. 4a and produced maps in Fig. 4d. Average EEL spectra of Fe at (top of Fig. 4d) were obtained from the regions labelled I and II in Fig. 4d. The differences reflect differences in average valence. The map at the bottom of Fig $4 \mathrm{~d}$ was obtained using 0.5 $\mathrm{eV}$ wide windows on the Fe L-edge at the positions marked $-\mathrm{L}_{2}-706 \mathrm{eV}$ (yellow) and $\mathrm{L}_{3}-708 \mathrm{eV}$ (green). This map (Fig. 4d) clearly shows mixed valence states $\left(\mathrm{Fe}^{2+} / \mathrm{Fe}^{3+}\right)$ within the region. Recent works (Joseph et al., 2015; Li et al., 2012; Quin et al., 2015) have all noted the possible role of iron with a mixed oxidation state in redox process on the surface of biochars and in soil. 


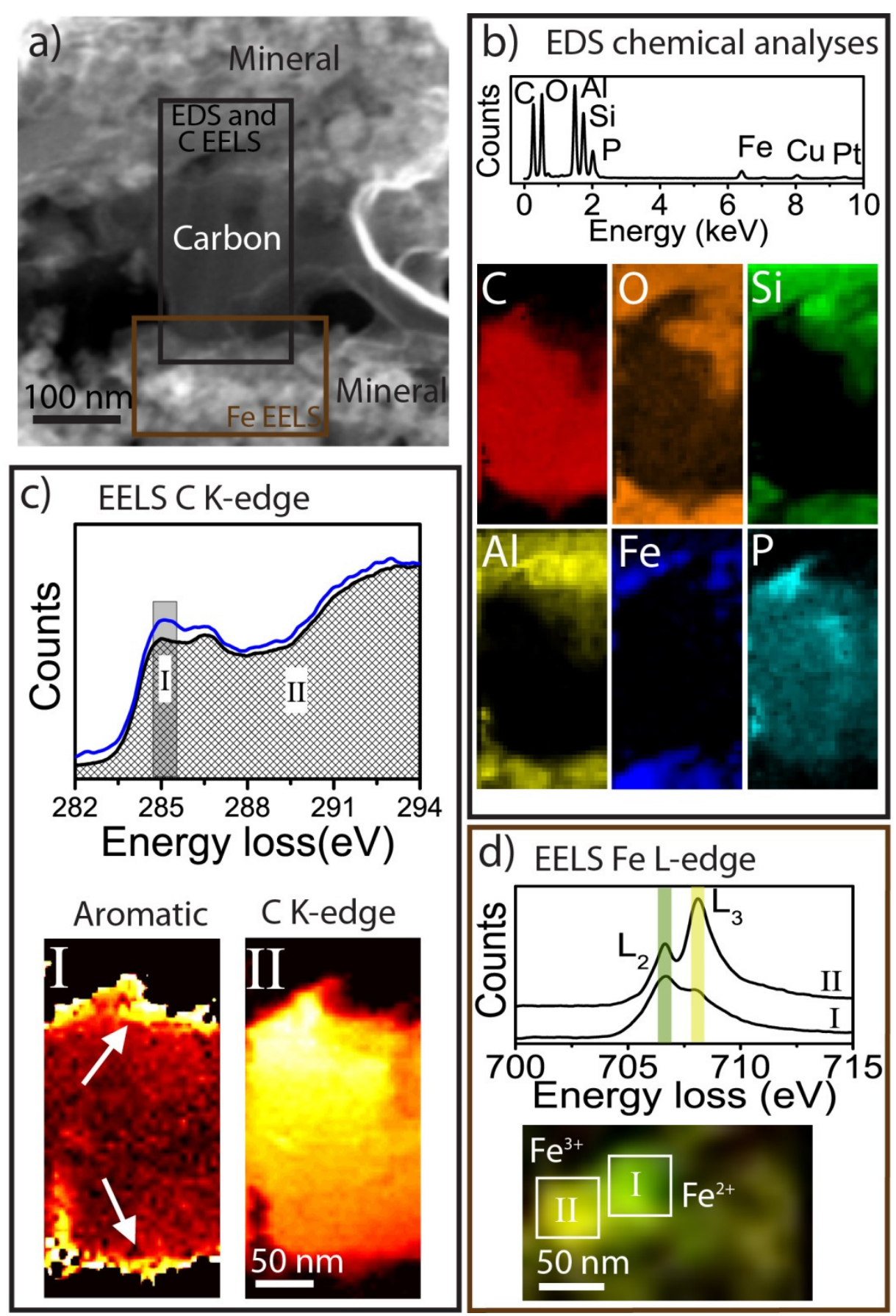

Figure 4. STEM nanoscale analyses of a biochar organo-mineral interface of GWS a) STEM-HAADF image of the organo-mineral interface. The two rectangular regions of interest are where chemical analyses were performed. b) Top: EDS spectrum image data obtained from the upper region of interest in a). Bottom: EDS maps show the elemental distribution of the $\mathrm{C}, \mathrm{O}, \mathrm{Si}, \mathrm{Al}, \mathrm{Fe}$, and $\mathrm{P} . \mathrm{Cu}$ and $\mathrm{Pt}$ signals in the EDS spectrum come from the TEM grid and the Pt protection layer, respectively. c) EELS C K-edge spectra (top) and maps (bottom) obtained from the upper region of interest in a). The upper (blue) spectrum has been slighted shifted upwards after normalisation to highlight the differences at c.a. $285 \mathrm{eV}$. Map I was obtained using the energy window I at $285 \mathrm{eV}$ and 
it shows the distribution of aromatic functionality. Map II shows the C K-edge integrated signal. d) Spectra (top) and maps (bottom) obtained from the lower region of interest in Fig. 4a labelled as Fe EELS. Fe L-edge EEL spectra, respectively obtained from the square regions (marked I and II) in the map. This colour mix map shows the distributions of iron mixed valence states $\left(\mathrm{Fe}^{2+} / \mathrm{Fe}^{3+}\right)$.

\subsection{Analysis of Kon-Tiki Biochar (WC)}

SEM results of WC are shown in Fig. 5. The surface of WC biochar has been altered during composting with a range of secondary minerals/inorganic compounds present on the biochar surface and in the pores (Fig. 5a and b) (Kammann et al., 2015). Agglomerates of sub-micron phases have formed which are bonded together to form organo-mineral associations on specific sites on the surface of the biochar (see Fig. S3 in the Support Information). The insets show the EDS spectra of the fields of view. These contain $\mathrm{Fe}, \mathrm{Si}, \mathrm{S}, \mathrm{Ca}, \mathrm{Mg}, \mathrm{K}$, and $\mathrm{P}$ as the major components. $\mathrm{Ca}$ is also found in the pores of the biochar carbon matrix as bright regions in in Fig. 5c, and in detail in Fig. 5d. Calcium-rich regions also contained magnesium, but little else.

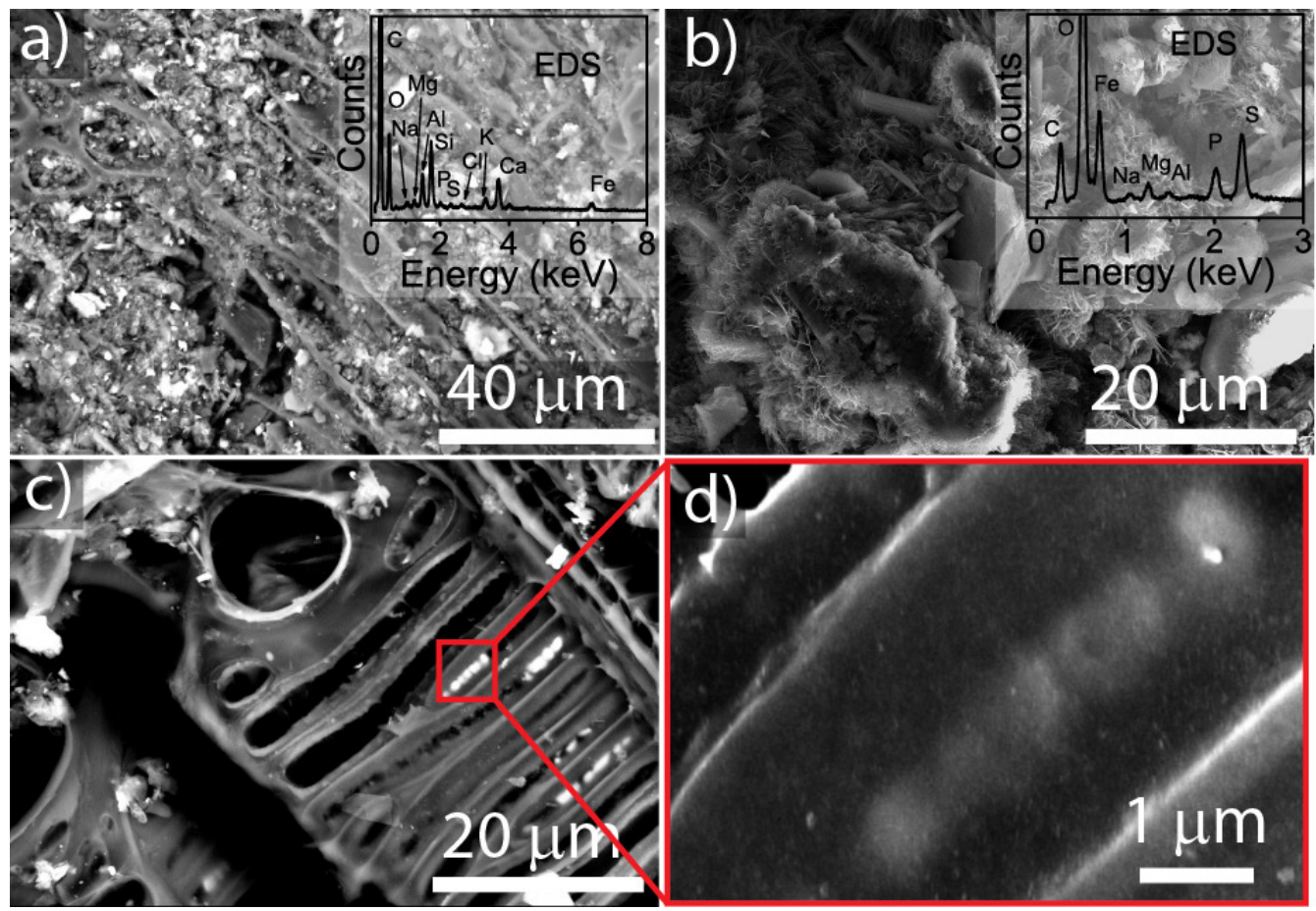

Figure 5. a) and b) Secondary electron SEM micrographs of the surface of the composted WC biochar partially coated with both organic and inorganic matter. The insets show EDS spectra collected over the field of view. c) and d) are SE images of the surface of the WC in a region with high concentration of calcium (bright areas). 
In Fig. 6 a STEM-HAADF images of a microtomed section from a composted Kon-Tiki biochar are shown. The gold coating of the biochar particle prior to embedding for ultramicrotomy (sample preparation for STEM) provided a high contrast fiducial marker delineating the original surface of the particle in the microtomed sections (Fig. 6a). A porous layer between the gold and the homogenous carbon matrix was clearly identified (Fig. 6a and b). This layer on the surface of the biochar particles has a fairly uniform structure, but variable thickness (several $\mathrm{nm}$ to $500 \mathrm{~nm}$ ). Ultramicrotomy did not produce significant compression or damage in this layer. In contrast, the brittle biochar showed parallel striations and some fracture, due to blade chatter in the ultramicrotome.

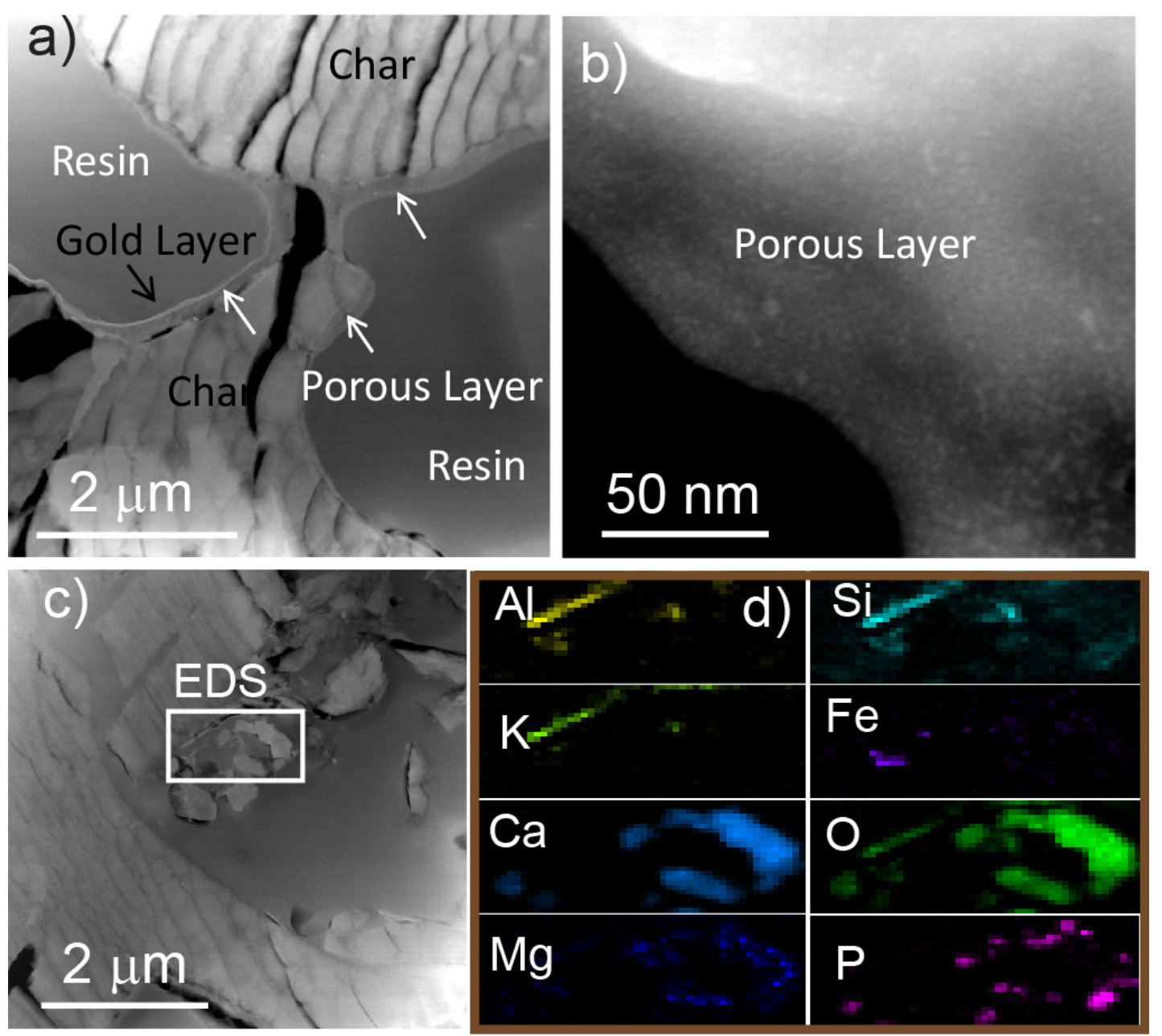

Figure 6. STEM-HAADF images $(60 \mathrm{kV})$ of a microtomed slice from a composted Kon-Tiki biochar (WC). a) Biochar particle embedded in resin showing the porous layer on top of the biochar. The large resin filled pore on the right shows poor coverage with sputtered gold, due to a shadowing effect. The more exposed pore (top left) shows better coverage. b) Detailed view of the porous layer. c) Another sectioned region showing a group of mineral particles at the surface of WC. d) X-ray maps (EDS) of the boxed region in c). 
In cross-section it was apparent that some quite large mineral particles $(\sim 1 \mu \mathrm{m})$ formed on the original pore surface (Fig. 6c). X-ray mapping (Fig. 6d) revealed a number of different phases. The largest blocky particles (Ca-rich) are most likely $\mathrm{CaCO}_{3}$, while the smaller plate like particles are alumina-silicate clay. Much smaller discrete particles of iron oxides and phosphates are also present. Higher magnification imaging on this, and other regions (not shown), revealed that the mineral phase ensembles were bound together by organic layers to form micro-agglomerates.

In Fig. 7, additional STEM HAADF, with EELS measurements on the $\mathrm{C}$ and $\mathrm{N}$ K-edges were carried out in the porous layer with a view to identifying the presence of carbon and nitrogen functional groups. Measurements were made at liquid nitrogen temperature and low voltage $(60 \mathrm{kV})$ to reduce the impact of beam damage and to suppress carbon contamination caused by mobile (at room temperature) hydrocarbons cracking under the beam (Mitchell, 2015). The porous layer identified in Fig. 7a was probed and additional features (labelled $a$ to $e$ in Fig. 7a and b) were found in the $\mathrm{C}$ and $\mathrm{N}$ K-edges. Based on literature reported values (Gillespie et al., 2014; Jokic et al., 2004; Keiluweit et al., 2012; Leinweber et al., 2009) N peaks were assigned to the following functional groups: pyridine $(398.8 \mathrm{eV})$, imine $(400.0 \mathrm{eV})$, amide/peptide $(401.5 \mathrm{eV})$, pyrrolic $(402.8 \mathrm{eV})$ and $\mathrm{NO}_{2}{ }^{-}$\%oxidised $\mathrm{N}(403.7 \mathrm{eV})$, whereas at the equivalent region (porous layer), the EELS of the C K-edge (Fig. 7a lower spectrum) revealed a spectrum typical of amorphous $\mathrm{C}$, where no functional groups were found. Fig. $7 \mathrm{~b}$ shows the EELS from the porous organic layer. $\mathrm{C} \mathrm{K}$-edge spectra showing peaks corresponding to functional carbon groups: a-285.1 eV $\rightarrow$ aromatic, b-286.1 eV $\rightarrow$ aromatic with side chain, c$286.8 \mathrm{eV} \rightarrow$ ketone, $\mathrm{d}-287.3 \mathrm{eV} \rightarrow$ aliphatic, and e-288.1eV $\rightarrow$ carboxyl/amine carbon were observed (Keiluweit et al., 2012; Keiluweit et al., 2010; Lehmann et al., 2009; Obst et al., 2011). 

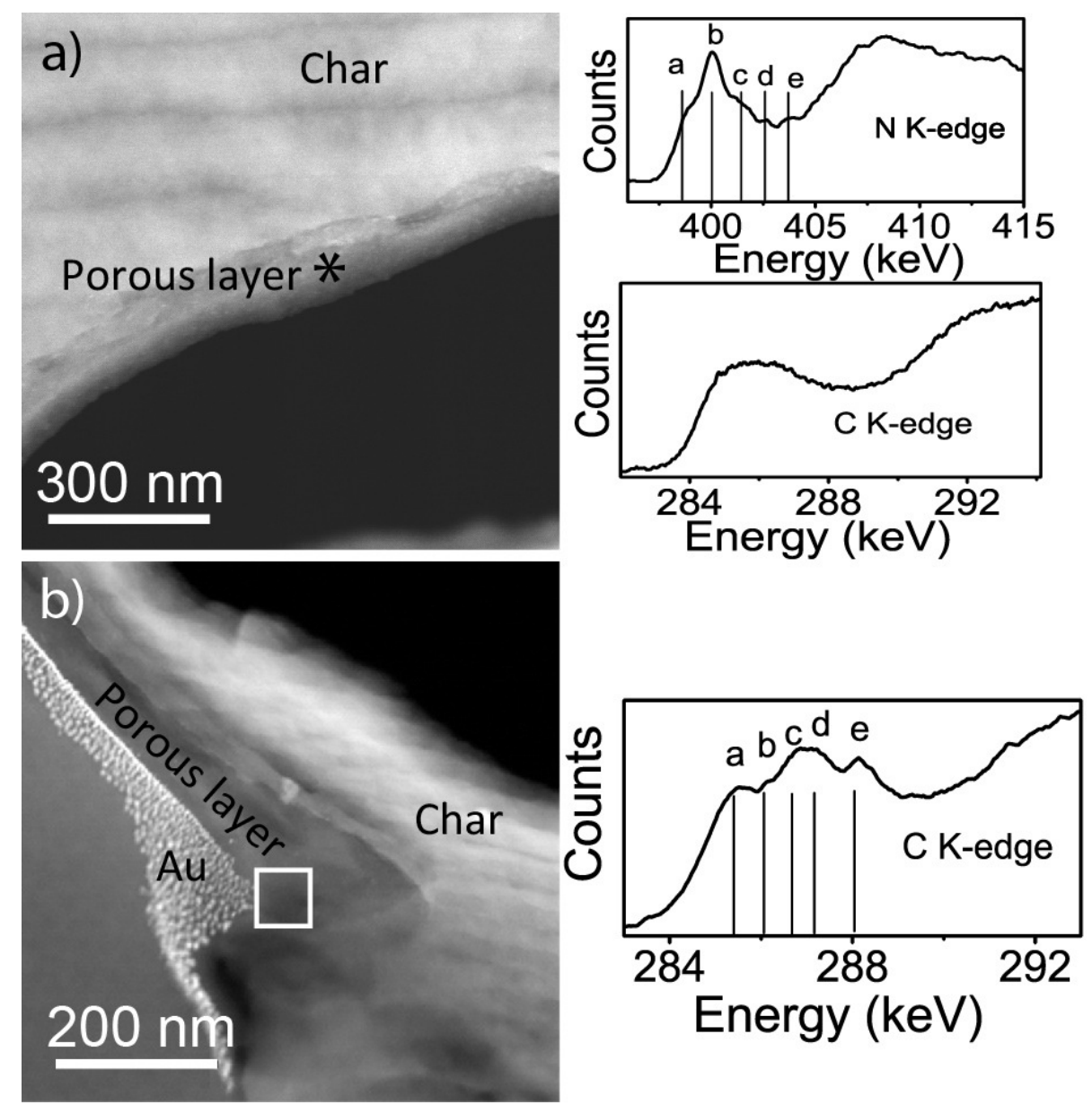

Figure 7. STEM - HAADF images $(60 \mathrm{kV})$ and N K and C K-EEL spectra collected using cold stage microscopy of composted WC biochar. a) Left - STEM-HAADF image showing a cross section through the porous layer. $\mathrm{N}$ K-edge spectra were acquired (right) at the point marked with * Peaks due to $\mathrm{N}$-containing functional groups are observed and marked a-e (see text for detailed explanation). Centre right $-\mathrm{C}$ K-EEL spectrum taken from the biochar matrix and shows a broad peak from $285.1 \mathrm{eV}$ to 287.3 $\mathrm{eV}$ indicating a low concentration of $\mathrm{C} / \mathrm{O}$ functional groups and a high concentration of amorphous carbon. b) Left - STEM-HAADF image of another region of the porous layer. Bottom right - C K-edge spectra obtained from the boxed region in b). Peaks due to carbon-containing functional groups in the EELS are labelled $a$ to $e: \mathrm{a}-285.1 \mathrm{eV} \rightarrow$ aromatic, b-286.1 eV $\rightarrow$ aromatic with side chain, c-286.8 eV $\rightarrow$ ketone, d-287.3 eV $\rightarrow>$ aliphatic, and e-288.1eV $\rightarrow$ carboxyl/amine carbon. 


\section{Discussion}

\subsection{Analysis of Mineral Rich Biochar (RCBS)}

The RCBS biochar has been recovered from a paddy soil, i.e. an environment where there has been both flooding and drying periods. During flooding the redox potential of the soil is typically reduced (Kirk, 2004) and biochars will exist in an anoxic environment. During drying the soil becomes aerated again and any reduced elements that are exposed to air will oxidise (Kirk, 2004). This could explain the presence of $\mathrm{Fe} / \mathrm{O}$ compounds with both $\mathrm{Fe}^{2+}$ and $\mathrm{Fe}^{3+}$ oxidation state noted in the EEL spectra (top inset in Fig, 2c). SEM images (Fig. 1) show a well-defined organo-mineral layer formed on the surface of the vascular structure (formed from the carbonisation of the phloem and xylem of the woody biochar). In some areas this layer covers the biochar surface and in other areas the biochar surface is partly covered indicating a complex series of surface reactions have taken place over the three years after incorporation. Since there are 2 rice crops every year, minerals, cations and anions and dissolved organic matter can be adsorbed and desorbed. This could partly explain the heterogeneous nature of the mineral/inorganic compounds detected on the external and internal surface of the biochars.

The sample preparation method impregnation with Spurr's resin followed by ultramicrotomy was very effective in obtaining large electron-transparent areas for TEM analyses. Figure 2 shows that RCBS woody biochar has a multi-layer complex structure. The outer surface of the biochar particle is coated with a layer of inorganic compounds and/or minerals rich in $\mathrm{Fe}, \mathrm{Al}, \mathrm{Si}$ and $\mathrm{P}$ and organic compounds. These form on the external surface of the biochar and on the walls of the large exposed pores (diameter $>1 \mu \mathrm{m}$ ). This coating is dominated by the formation of $\mathrm{Fe} / \mathrm{O}$ (mainly $\mathrm{Fe}_{3} \mathrm{O}_{4}$ ), $\mathrm{SiO}_{2}$ and possibly $\mathrm{Fe} / \mathrm{P}$ nanometre sized phases. This is consistent with the findings of Kirk (2004) where the oxidation and reduction of Fe and the availability of Si play a major role in the rice growing cycle. Fe/O-rich regions on the surface of biochar could play a signifcant role in reducing greenhouse emissions (Quin et al., 2015) making nutrients more available through the so called redox wheel effect ( $\mathrm{Li}$ et al., 2012). Further detailed investigation is required to confirm the role of these $\mathrm{Fe} / \mathrm{O}$ nanoparticles with mixed oxidation state. The nanosized mineral phases are bound together by a gluelike organic phase to form a micro-agglomerate. 


\subsection{Analysis of Green Waste Biochar (GWS)}

This biochar had been incorporated in a rhodic Ferralsol in a subtropical pasture (high rainfall) for over 9.5 years. Previous examination after 1 year revealed considerable surface interaction between the soil organic and mineral matter and biochar (Joseph et al., 2010). After being incorporated in the soil for 9.5 years, the SEM (Fig. 3) and TEM images (Fig. 4) of the GWS sample provided more details of the external organomineral layer covering the porous surface of biochar (Fig. 3a and 4a). Biochar particles were not covered uniformly by this layer. There was considerable deformation on the edge of the biochar carbon matrix where there was no protection from the organomineral layer (Fig. 3a). Figure 3b shows that these heterogeneous organo-mineral layers can form inside the pores. Figure S1 reveals a series of porous micro-aggregates that are bound together probably by amorphous carbon to form complex porous, organo-mineral associations on the biochar surface. Further research is required to determine if the reaction regime in a pore is different to that on the surface as proposed by Joseph et al. (Joseph et al., 2013).

The EELS analysis (Fig. 4) of the mineral biochar interface shows that these regions are richer in aromatic carbon $(285 \mathrm{eV})$ when compared to biochar regions not at the mineral interface. This would indicate that there has been reactions between the carbon matrix and the mineral layer in this area resulting in either the removal of organic compounds that have little aromaticity in the biochar (Weng et al., 2015) or the catalysis of decomposition of dissolved organic matter from the soil that has led to the formation of organic compounds that have high aromaticity (Kalbitz et al., 2003; Singh and Cowie, 2014). It also could have originated from the adsorption of organic compounds in the soil that have high aromaticity (Marschner and Kalbitz, 2003). It is also possible that the $\mathrm{Al} / \mathrm{Si} / \mathrm{Fe} / \mathrm{O}$ minerals/inorganic compounds existed on the surface of the greenwaste before pyrolysis as this material laid on a clayey soil at a waste management site before being collected and pyrolysed. Rawal et al. (Rawal et al., 2016), using NMR spectroscopy, examined a biochar produced from bamboo impregnated with clay and $\mathrm{FeSO}_{4}$ and compared this with biochar made from untreated bamboo. They showed that the interaction between carbon, clay and $\mathrm{FeSO}_{4}$ during pyrolysis increased aromatic carbon content in biochar. No nitrogen functional groups were detected in the same area. These results also agree with the results of the field trials using this biochar (Slavich et al., 2013). They found that this GWS biochar increased the content of stable soil carbon but did not increase soil nitrogen content. This finding was further supported 
by work from Weng et al., (2015) showing that a similar biochar on the same soil and pasture management induced a short-term (60 days) negative priming, followed by a longer-term positive priming (stabilisation of new soil $\mathrm{C}$ deposits).

\subsection{Analysis of Kon-Tiki Biochar (WC)}

Compost has a much higher content of organic matter than most soils and during the composting process the temperature becomes much higher $\left(50-70^{\circ} \mathrm{C}\right)$ than soil. Both the $\mathrm{pH}$ and the Eh of the compost pile can change significantly over the 4-8 weeks of composting (Kammann et al., 2016). SEM imaging provided high quality topographic information which showed that inorganic phases covered only part of the woody biochar's surface. The SEM images of the WC biochar showed differences (Fig. 5) in the type of minerals/inorganic compounds that formed on the surface and in the macroporous region when compared with RCBS (Fig. 1) and GWS (Fig. 3) biochars. Figure $5 \mathrm{~b}$ shows the formation of a series of different inorganic phases that are bonded together with organic compounds to form micro-agglomerates. There are regions where fine crystals are formed that have diameters less than 1 micrometre. These were not observed in the other two samples and Fig. 5d shows increased concentrations of $\mathrm{Ca}$ inside the carbon matrix of the biochar. This indicates that there could be a difference in the biotic and abiotic interactions/reactions of the biochar in the compost and the two biochars in the soil. Fig. S3 shows that these micro-aggregates appear to bind together to form micro-aggregate associations although the morphology appears to be different to those seen in the other two samples.

Identifying non-biochar carbon species on the biochar surface is not possible with SEM EDS. Thus STEM analysis on microtomed ultra-thin sections was used. Using STEM, we were able to detect and characterise a porous organo-mineral layer that formed on the walls of the pores of the biochar. The porous organo-mineral layer was several 10100 nanometres thick, and covered parts of surface of the biochar. Gold coating of the biochar prior to embedding enabled us to clearly identify the original sample surface. Rather thin gold coating on rather thick organo-mineral layer led to the conclusion that this layer predominantly is formed inside macro-pores of the biochar and not on outer surfaces. EELS (Fig. 7a) showed the presence of nitrogen-containing functional groups on the organo-mineral layer and a carbon phase (biochar) that has a high aromatic content and very little oxygen functionality. In a similar vein, C K-edge EELS data (Fig. 7b) suggests that the layer is not a modification of the biochar carbon matrix, but rather 
it is sorbed compost organic matter (OM) containing a range of organic functional groups. The porous organo-mineral layer could be formed from the interaction of compost organic matter and mineral ions at the biochar surface (ostensibly carbon), as has been discussed for organo-mineral interactions in soil (Kleber et al., 2007). Joseph et al. (2010) and Kleber et al. (2007) suggested that positively charged mineral compounds would be attracted to the negatively charged carbon surface of the biochar. Due to the high $\mathrm{pH}$ of any liquid layer formed on the surface of the biochar, dissolved mineral matter could precipitate on the surface of the biochar as seen in Fig. 5b. Negatively charged dissolved organic matter can bind to the positively charged mineral surfaces. The EELS analysis of the organo-mineral layer (Fig. 7b) indicates that these compounds have a high concentration of $\mathrm{C} / \mathrm{O}$ functional groups which would facilitate cation exchange with the nutrient-rich water in the compost. Thus, the organic matter would be complexed with more mineral matter. Similar structures have been observed previously (Archanjo et al., 2015; Jorio et al., 2012; Liang et al., 2013) for Amazon Anthrosols, where the organic-mineral layer protects the inner black carbon material. The porous organo-mineral layer might play an important role in the beneficial properties of composted biochar on plant growth and nitrate retention (Kammann et al., 2015; Schulz and Glaser, 2012).

The above research has strongly indicated that high resolution spectroscopy at the nanometre scale can be carried out without damage to the carbon and mineral structure. We believe that the effect of reducing the microscope voltage from $200 \mathrm{kV}$ to $80 \mathrm{kV}$ or $60 \mathrm{kV}$ must be utilised when examining these porous organo-mineral layers. Previous STEM/TEM examination of graphene and carbon nanotubes have found that the reduction in beam energy from $80 \mathrm{kV}$ to $60 \mathrm{kV}$ greatly minimized knock-on damage (Egerton, 2013) and that voltages above $80 \mathrm{kV}$ rapidly damage the specimen (Li et al., 2014). Also, it is well known that utilising cryo techniques, for soft materials, such as polymers (Cheng et al., 2012) significantly increase material stability under the electron beam avoiding for instance damage by decarboxylation in functional groups T $200-250$ ${ }^{\circ} \mathrm{C}$ (Kuo et al., 2013). These differences help to explain the EELS results among the samples.

\section{Conclusions}


In the introduction we have posed three questions. We have shown that the utilisation of high resolution microscopy has been able to give provide insights into the complex reactions which take place on the external and internal surfaces of biochar in soil and compost (question 1) and we have shown that there are considerable similarities and possibly some differences in the layers formed in different soils and compost (question 2). Analysis of the surfaces of the both the field applied biochars has revealed the formation of a heterogeneous non-uniform porous coating consisting of different mineral/inorganic compounds bonded together with organic compounds. The inorganic phases consisted of $\mathrm{Fe}, \mathrm{Al}, \mathrm{Si}$ oxides, phosphates $(\mathrm{Ca} / \mathrm{Fe} / \mathrm{Al})$, carbonates $(\mathrm{Ca} / \mathrm{Mg})$, and $\mathrm{K}$, and had dimensions from a few nanometres up to $>50 \mathrm{~nm}$. The Fe/O particles have a mixed oxidation (II and III) states and were identified as magnetite and hematite. The coatings are few to several hundred of nanometres thick, heterogeneous concerning the content of carbon and comprised a range of organic compounds that might have a high concentration of oxygen and nitrogen functional groups as well as a detectable concentration of P. On some biochar surfaces micro-agglomerates of various inorganic phases are bonded together by organic compounds to form organo-mineral associations. High resolution SEM of the surfaces of the macropores in the field applied biochars indicated that there were differences in the type and distribution of mineral phases that had bonded to the walls of the carbon matrix. Further detailed analysis is required to confirm these findings using techniques that can do detailed quantification over a wider area of the particle (e.g. laser ablation ICP-MS).

We also observed in the composted sample that the carbon matrix at the surface of the biochar does not appear to have a high concentration of $\mathrm{C} / \mathrm{O}$ functional groups. On the GWS biochar, we observed a higher degree of aromaticity at the interface of the char with the organo-mineral layer than in an area 10-20 nm away from the interface. This higher aromaticity occurred next to a $\mathrm{Fe} / \mathrm{O}$ particle with a mixed oxidation state indicating that there could have been reactions with the mineral phase, possibly involving $\mathrm{Fe}$ as an electron acceptor or donor. Microtomed samples have revealed the complex nature of the internal pores of the woody biochars next to the outer organomineral layer. It was found that a range of inorganic phases where formed on the surface of these internal pores. These phases are probably positively charged and could be responsible for adsorption of negatively charged nitrate ions. 
In answering question 3 we conclude that the choice of TEM sample preparation plays an important role for the detection of functional groups. FIB and a novel $\mathrm{Au}$ coating/cryo-ultramicrotomy method produced excellent results, enabling the original surface of the biochar to be sectioned, identified and characterised. Differences in results were obtained for samples examined either at room temperature/high voltage $(200 \mathrm{kV})$, compared with those obtained at low temperature $\left(-196^{\circ} \mathrm{C}\right) /$ low voltage $(60$ $\mathrm{kV}$ ). Lowering the voltage helps to reduce the effects of knock-on damage caused by energetic electrons. Lowering the specimen temperature reduces the sensitivity to damage and eliminates carbon contamination caused by diffusion of mobile hydrocarbons on the specimen surface.

Analytical SEM and TEM/STEM provide the ability to analyse $\mathrm{C}$ and $\mathrm{N}$ functional groups and associated inorganic/mineral compounds at a spatial resolution down to the nanoscale. This analysis can assist in understanding how biochars reacts with different soil components (minerals, microbes, organic matter) and plants as a function of agronomic practice and environmental factors.

\section{Acknowledgements}

B. S. A., M. E. M., C. A. A. and J. R. A. would like to thank CNPq, FINEP and FAPERJ for financial support. S. J., P. M. and S. D. would like to acknowledge funding from the Australia Government and Renewed Carbon Pty. through the ARC Linkage Grant and through DAFF Carbon Farming Futures Filling the Research Gap (RG134978) and the support of the Electron Microscope Units at the University of Newcastle and NSW. M. A. acknowledges the financial support from European Union Seventh Framework Programme under Grant Agreement 312483 - ESTEEM II (Integrated Infrastructure Initiative-I3). We identify certain commercial equipment, instruments, or materials in this article to specify adequately the experimental procedure. In no case does such identification imply recommendation or endorsement, nor does it imply that the materials or equipment identified are necessarily the best available for the purpose. 


\section{References}

Araujo, J.R., Archanjo, B.S., de Souza, K.R., Kwapinski, W., Falcao, N.P.S., Novotny, E.H., Achete, C.A., 2014. Selective extraction of humic acids from an anthropogenic Amazonian dark earth and from a chemically oxidized charcoal. Biol. Fertil. Soils 50(8), 1223-1232.

Archanjo, B.S., Araujo, J.R., Silva, A.M., Capaz, R.B., Falcao, N.P.S., Jorio, A., Achete, C.A., 2014. Chemical Analysis and Molecular Models for Calcium-OxygenCarbon Interactions in Black Carbon Found in Fertile Amazonian Anthrosoils. Environ. Sci. Technol. 48(13), 7445-7452.

Archanjo, B.S., Baptista, D.L., Sena, L.A., Cancado, L.G., Falcao, N.P.S., Jorio, A., Achete, C.A., 2015. Nanoscale mapping of carbon oxidation in pyrogenic black carbon from ancient Amazonian anthrosols. Environ. Sci. Process. Impacts 17(4), 775-779.

Borchard, N., Spokas, K., Prost, K., Siemens, J., 2014. Greenhouse Gas Production in Mixtures of Soil with Composted and Noncomposted Biochars Is Governed by Char-Associated Organic Compounds. J. Environ. Qual. 43(3), 971-979.

Cheng, C.H., Lehmann, J., Thies, J.E., Burton, S.D., Engelhard, M.H., 2006. Oxidation of black carbon by biotic and abiotic processes. Org. Geochem. 37(11), 1477-1488.

Cheng, D., Mitchell, D.R.G., Shieh, D.-B., Braet, F., 2012. Practical Considerations in the Successful Preparation of Specimens for Thin-Film Cryo-Transmission Electron Microscopy. In: A. Méndez-Vilas (Ed.), Current Microscopy Contributions to Advances in Science and Technology. Formatex Research Center, Spain, pp. 880-890.

Chia, C.H., Munroe, P., Joseph, S.D., Lin, Y., Lehmann, J., Muller, D.A., Xin, H.L., Neves, E., 2012. Analytical electron microscopy of black carbon and microaggregated mineral matter in Amazonian dark Earth. J. Microsc. 245(2), 129-139.

Cornelissen, G., Pandit, N.R., Taylor, P., Pandit, B.H., Sparrevik, M., Schmidt, H.P., 2016. Emissions and Char Quality of Flame-Curtain "Kon Tiki" Kilns for Farmer-Scale Charcoal/Biochar Production. Plos One 11(5).

Egerton, R.F., 2013. Control of radiation damage in the TEM. Ultramicroscopy 127, 100-108.

Gillespie, A.W., Diochon, A., Ma, B.L., Morrison, M.J., Kellman, L., Walley, F.L., Regier, T.Z., Chevrier, D., Dynes, J.J., Gregorich, E.G., 2014. Nitrogen input quality changes the biochemical composition of soil organic matter stabilized in the fine fraction: a long-term study. Biogeochemistry 117(2-3), 337-350.

Hale, S.E., Alling, V., Martinsen, V., Mulder, J., Breedveld, G.D., Cornelissen, G., 2013. The sorption and desorption of phosphate-P, ammonium-N and nitrate- $\mathrm{N}$ in cacao shell and corn cob biochars. Chemosphere 91(11), 1612-1619.

Hale, S.E., Endo, S., Arp, H.P.H., Zimmerman, A.R., Cornelissen, G., 2015. Sorption of the monoterpenes $\alpha$-pinene and limonene to carbonaceous geosorbents including biochar. Chemosphere 119, 881-888.

Heitkötter, J., Marschner, B., 2015. Interactive effects of biochar ageing in soils related to feedstock, pyrolysis temperature, and historic charcoal production. Geoderma 245-246, 56-64.

Jokic, A., Cutler, J.N., Anderson, D.W., Walley, F.L., 2004. Detection of heterocyclic N compounds in whole soils using N-XANES spectroscopy. Can. J. Soil Sci. 84(3), 291-293. 
Jorio, A., Ribeiro-Soares, J., Cancado, L.G., Falcao, N.P.S., Dos Santos, H.F., Baptista, D.L., Ferreira, E.H.M., Archanjo, B.S., Achete, C.A., 2012. Microscopy and spectroscopy analysis of carbon nanostructures in highly fertile Amazonian anthrosoils. Soil Till. Res. 122, 61-66.

Joseph, S., Graber, E.R., Chia, C., Munroe, P., Donne, S., Thomas, T., Nielsen, S., Marjo, C., Rutlidge, H., Pan, G.X., Li, L., Taylor, P., Rawal, A., Hook, J., 2013. Shifting paradigms: development of high-efficiency biochar fertilizers based on nano-structures and soluble components. Carbon Manag. 4(3), 323-343.

Joseph, S., Husson, O., Graber, E.R., van Zwieten, L., Taherymoosavi, S., Thomas, T., Nielsen, S., Ye, J., Pan, G., Chia, C., Munroe, P., Allen, J., Lin, Y., Fan, X., Donne, S., 2015. The Electrochemical Properties of Biochars and How They Affect Soil Redox Properties and Processes. Agronomy-Basel 5(3), 322-340.

Joseph, S.D., Camps-Arbestain, M., Lin, Y., Munroe, P., Chia, C.H., Hook, J., van Zwieten, L., Kimber, S., Cowie, A., Singh, B.P., Lehmann, J., Foidl, N., Smernik, R.J., Amonette, J.E., 2010. An investigation into the reactions of biochar in soil. Aust. J. Soil Res. 48(6-7), 501-515.

Kalbitz, K., Schmerwitz, J., Schwesig, D., Matzner, E., 2003. Biodegradation of soilderived dissolved organic matter as related to its properties. Geoderma 113(3-4), 273-291.

Kammann, C.I., Glaser, B., Schmidt, H.P., 2016. Combining Biochar and Organic Amendments. In: S. Shackley, G. Ruysschaert, K. Zwart, B. Glaser (Eds.), Biochar in European Soils and Agriculture: Science and Practice. Taylor \& Francis, pp. 136-164.

Kammann, C.I., Schmidt, H.P., Messerschmidt, N., Linsel, S., Steffens, D., Muller, C., Koyro, H.W., Conte, P., Stephen, J., 2015. Plant growth improvement mediated by nitrate capture in co-composted biochar. Sci. Rep. 5.

Kappler, A., Wuestner, M.L., Ruecker, A., Harter, J., Halama, M., Behrens, S., 2014. Biochar as an Electron Shuttle between Bacteria and Fe(III) Minerals. Environ. Sci. Technol. Lett. 1(8), 339-344.

Keiluweit, M., Bougoure, J.J., Zeglin, L.H., Myrold, D.D., Weber, P.K., Pett-Ridge, J., Kleber, M., Nico, P.S., 2012. Nano-scale investigation of the association of microbial nitrogen residues with iron (hydr)oxides in a forest soil 0 horizon. Geochim. Cosmochim. Acta 95, 213-226.

Keiluweit, M., Nico, P.S., Johnson, M.G., Kleber, M., 2010. Dynamic Molecular Structure of Plant Biomass-Derived Black Carbon (Biochar). Environ. Sci. Technol. 44(4), 1247-1253.

Kirk, G., 2004. The Biogeochemistry of Submerged Soils. Wiley, Chichester.

Kleber, M., Sollins, P., Sutton, R., 2007. A conceptual model of organo-mineral interactions in soils: self-assembly of organic molecular fragments into zonal structures on mineral surfaces. Biogeochemistry 85(1), 9-24.

Klüpfel, L., Keiluweit, M., Kleber, M., Sander, M., 2014. Redox Properties of Plant Biomass-Derived Black Carbon (Biochar). Environ. Sci. Technol. 48(10), 5601-5611.

Kuo, D.T.F., Vander Sande, J.B., Gschwend, P.M., 2013. Characterization of black carbon in geosorbents at the nanometer scale by STEM-EDX elemental mapping. Org. Geochem. 56, 81-93.

Lehmann, J., Joseph, S., 2009. Biochar for Environmental Management: Science and Technology. Earthscan, London. 
Lehmann, J., Rillig, M.C., Thies, J., Masiello, C.A., Hockaday, W.C., Crowley, D., 2011. Biochar effects on soil biota - A review. Soil Biol. Biochem. 43(9), 18121836.

Lehmann, J., Solomon, D., Brandes, J., Fleckenstein, H., Jacobson, C., Thieme, J., 2009. Synchrotron-Based Near-Edge X-Ray Spectroscopy of Natural Organic Matter in Soils and Sediments, Biophysico-Chemical Processes Involving Natural Nonliving Organic Matter in Environmental Systems. John Wiley \& Sons, Inc., pp. 729-781.

Leinweber, P., Walley, F., Kruse, J., Jandl, G., Eckhardt, K.U., Blyth, R.I.R., Regier, T., 2009. Cultivation Affects Soil Organic Nitrogen: Pyrolysis-Mass Spectrometry and Nitrogen K-edge XANES Spectroscopy Evidence. Soil Sci. Soc. Am. J. 73(1), 82-92.

Li, B., Feng, Y., Ding, K.-w., Qian, G., Zhang, X.-b., Liu, Y.-f., 2014. Effect of electron beam irradiation on multi-walled carbon nanotubes. Trans. Nonferrous Met. Soc. China 24(3), 764-769.

Li, Y., Yu, S., Strong, J., Wang, H., 2012. Are the biogeochemical cycles of carbon, nitrogen, sulfur, and phosphorus driven by the "FeIII-FeII redox wheel" in dynamic redox environments? J. Soils Sed. 12(5), 683-693.

Liang, B., Wang, C., Solomon, D., Kinyangi, J., Luizăo, F.J., Wirick, S., Skjemstad, J.O., Lehmann, J., 2013. Oxidation is Key for Black Carbon Surface Functionality and Nutrient Retention in Amazon Anthrosols. British Journal of Environment and Climate Change 3(1), 15.

Lin, Y., Munroe, P., Joseph, S., Henderson, R., 2012. Migration of dissolved organic carbon in biochars and biochar-mineral complexes. Pesq. Agropec. Bras. 47(5), 677-686.

Marschner, B., Kalbitz, K., 2003. Controls of bioavailability and biodegradability of dissolved organic matter in soils. Geoderma 113(3-4), 211-235.

Mitchell, D.R.G., 2015. Contamination mitigation strategies for scanning transmission electron microscopy. Micron 73, 36-46.

Mohammadi, A., Cowie, A., Anh Mai, T.L., de la Rosa, R.A., Kristiansen, P., Brandão, M., Joseph, S., 2016. Biochar use for climate-change mitigation in rice cropping systems. J. Clean. Prod. 116, 61-70.

Obst, M., Grathwohl, P., Kappler, A., Eibl, O., Peranio, N., Gocht, T., 2011. Quantitative High-Resolution Mapping of Phenanthrene Sorption to Black Carbon Particles. Environ. Sci. Technol. 45(17), 7314-7322.

Pagano, M.C., Ribeiro-Soares, J., Cançado, L.G., Falcão, N.P.S., Gonçalves, V.N., Rosa, L.H., Takahashi, J.A., Achete, C.A., Jorio, A., 2016. Depth dependence of black carbon structure, elemental and microbiological composition in anthropic Amazonian dark soil. Soil Till. Res. 155, 298-307.

Quilliam, R.S., Glanville, H.C., Wade, S.C., Jones, D.L., 2013. Life in the 'charosphere' Does biochar in agricultural soil provide a significant habitat for microorganisms? Soil Biol. Biochem. 65, 287-293.

Quin, P., Joseph, S., Husson, O., Donne, S., Mitchell, D., Munroe, P., Phelan, D., Cowie, A., Van Zwieten, L., 2015. Lowering N20 emissions from soils using eucalypt biochar: the importance of redox reactions. Sci. Rep. 5, 16773.

Rawal, A., Joseph, S.D., Hook, J.M., Chia, C.H., Munroe, P.R., Donne, S., Lin, Y., Phelan, D., Mitchell, D.R.G., Pace, B., Horvat, J., Webber, J.B.W., 2016. MineralBiochar Composites: Molecular Structure and Porosity. Environ. Sci. Technol. 
Ribeiro-Soares, J., Oliveros, M.E., Garin, C., David, M.V., Martins, L.G.P., Almeida, C.A., Martins-Ferreira, E.H., Takai, K., Enoki, T., Magalhães-Paniago, R., Malachias, A., Jorio, A., Archanjo, B.S., Achete, C.A., Cançado, L.G., 2015. Structural analysis of polycrystalline graphene systems by Raman spectroscopy. Carbon 95, 646-652.

Schulz, H., Glaser, B., 2012. Effects of biochar compared to organic and inorganic fertilizers on soil quality and plant growth in a greenhouse experiment. J. Plant Nutr. Soil Sci. 175(3), 410-422.

Singh, B.P., Cowie, A.L., 2014. Long-term influence of biochar on native organic carbon mineralisation in a low-carbon clayey soil. Sci. Rep. 4.

Slavich, P.G., Sinclair, K., Morris, S.G., Kimber, S.W.L., Downie, A., Van Zwieten, L., 2013. Contrasting effects of manure and green waste biochars on the properties of an acidic ferralsol and productivity of a subtropical pasture. Plant and Soil 366(1-2), 213-227.

Spokas, K.A., 2013. Impact of biochar field aging on laboratory greenhouse gas production potentials. GCB Bioenergy 5(2), 165-176.

Spokas, K.A., Novak, J.M., Masiello, C.A., Johnson, M.G., Colosky, E.C., Ippolito, J.A., Trigo, C., 2014. Physical Disintegration of Biochar: An Overlooked Process. Environ. Sci. Technol. Lett. 1(8), 326-332.

Vallerot, J.-M., Bourrat, X., Mouchon, A., Chollon, G., 2006. Quantitative structural and textural assessment of laminar pyrocarbons through Raman spectroscopy, electron diffraction and few other techniques. Carbon 44(9), 1833-1844.

Weng, Z., Van Zwieten, L., Singh, B.P., Kimber, S., Morris, S., Cowie, A., Macdonald, L.M., 2015. Plant-biochar interactions drive the negative priming of soil organic carbon in an annual ryegrass field system. Soil Biol. Biochem. 90, 111-121.

Wiedner, K., Fischer, D., Walther, S., Criscuoli, I., Favilli, F., Nelle, O., Glaser, B., 2015. Acceleration of Biochar Surface Oxidation during Composting? J. Agric. Food. Chem. 63(15), 3830-3837. 